Desertion from the NHS has been compounded by a marked fall over the past decade in the number of new nurses being trained. In 1984 there were more than 75000 nursing students and pupil nurses in England. By 1994 that number had more than halved, and most of those in training were students on Project 2000 courses. $^{5}$ The move towards an "employer led" system, in which trusts take part in determining intakes to training, has led to a further reduction in the number of student nurses. Not all NHS trusts have adequate capabilities in workforce planning. An annex to an official letter (EL (95) 96) sent recently to all trusts by Ken Jarrold, director of human resources for the NHS Executive, notes that "long term trends suggest that current levels of training are unlikely to produce the number of qualified staff required unless there is a substantial reduction in the demand for nurses" in general and mental health nursing.

Nursing shortages have been cyclical in Britain, usually as a result of poor relative pay or increasing demand. Even in the United States, ${ }^{7}$ market forces and unfettered local pay determination, accompanied by low levels of workforce unionisation, have not prevented recurrent staffing shortages. ${ }^{1}$ With increasing demand for health care set to continue, the threat of nursing shortages is likely to remain. Breaking the cycle will require more investment in the information base; a recognition of the need to depoliticise shortages by loosening the link with pay determination; and a willingness to learn from past mistakes and from other countries. Establishing an independent national standing committee to exercise oversight and take a long term view of nurse workforce planning (as exists for the medical profession), and a general improvement in the workforce planning capabilities of NHS trusts, would go some way to keeping nursing shortages out of the headlines.

Queen Margaret College,

JAMES BUCHAN Reader in management

Edinburgh EH12 8TS

1 Buchan J. Flexibility or fragmentation? Trends and prospects in nurses pay. London: King's Fund Institute, 1992. (Briefing paper No 13.)

2 Secombe I, Patch A. Recruiting. Retaining and rewarding nurses in 1995. Brighton: Institute of Employment Studies, 1995. (Report No 295.)

Buchan J. Further flexing? NHS trusts and changing working patterns in NHS nursing. London: Royal College of Nursing, 1995.

4 Department of Health. Private hospitals, homes and clinics registered under section 23 of the registered homes act 1984. London: DoH, 1995.

5 Department of Health. Statistics bulletin 1995/18. London: DoH, 1995.

6 Aiken L. Transformation of the nursing workforce. Nursing Outlook 1995;43:201-9.

\title{
Homicides and suicides by mentally ill people
}

\author{
Systematic data collection cannot be left to the discretion of clinicians
}

The confidential inquiry into suicides and homicides by mentally ill people was set up in 1992 by Britain's Department of Health, following consultation with the Royal College of Psychiatrists. Its remit is to inquire into homicides and suicides committed by patients under the care of or recently discharged by, the specialist psychiatric services; to identify factors in the patients' management that might be related to the deaths; and to recommend preventive measures. A preliminary report on homicide was published in $1994,{ }^{1}$ followed this year by the publication of the inquiry's first full reports. ${ }^{2}$

The inquiry identified cases by searching through the Home Office records for homicides committed by anyone in whom a previous psychiatric history was noted or who subsequently became the responsibility of the specialist services under the powers of the Mental Health Act 1983. Suicides were notified on a voluntary basis by district psychiatric audit representatives. In both cases, information was subsequently obtained by questionnaires mailed to the named psychiatrist who had been involved in the patient's care immediately before death. In England and Wales, approximately 100 homicides a year are committed by people who are judged to be mentally abnormal at the time, ${ }^{2}$ and about $25-30 \%$ of suicides, $1200-1500$ cases annually, have had psychiatric contact within the preceding year. ${ }^{3}$ The inquiry's report into 39 cases of homicide and 240 cases of suicide identified over 18 months therefore represents a disappointing failure to achieve complete or unbiased case ascertainment.

The report notes: "It is striking that in many cases our respondents [the psychiatrists involved in each case], even with the benefit of complete confidentiality and with the opportunity to distance themselves from the distressing outcome which they were reporting, felt that death could not have been prevented by any measure which might have been adopted by the clinical team or the psychiatric service." Nonetheless the inquiry did identify problems in clinical practice and made a number of key recommendations: that clinical teams' risk assessment skills should be strengthened; that psychiatrists should spend more time with their patients; that genuinely multidisciplinary teams should be developed, along with better systems for communication between professionals; that professionals should be made more aware of appropriate uses of legal powers under the Mental Health Act 1983; and that treatment environments, whether in hospital or in the community, should be made acceptable to patients.

The 20 areas of concern about clinical practice listed in the report discussion of its findings will make familiar reading to those who have studied previous inquiries into individual cases. ${ }^{45}$ Two illustrations will suffice, both perhaps surprising to those without experience of routine psychiatry in the NHS. One is the frequency (up to $30 \%$ of cases) with which clinicians made management decisions about aggressive or suicidal patients without access to records about previous episodes of care. The other is the observation that psychiatrists do not always understand, or use appropriately, the powers they already have under the Mental Health Act 1983.

We have been here before, with the series of inquiries into standards of care in psychiatric hospitals which began in the late $1960 \mathrm{~s}^{5}$ In retrospect these were more a political than a scientific expedient, designed to manufacture a consensus around the hospital closure programme. The same danger faces the confidential inquiry; if it does not establish a sound research base its results will be used to support special pleading for community treatment orders, supervision registers, or more finances, rather than to inform rational debate.

The Department of Health has provided funding for the confidential inquiry's continuation after its first director retires, with the project now to be based at the University of Manchester. The relaunched inquiry has some major tasks to tackle. Firstly, it must strengthen the role of the local inquiry 
into individual cases. One approach would be to bring techniques from qualitative research ${ }^{6}$ to bear on the process of implementation, collation, and dissemination of results. Secondly, it should broaden its perspective. We need to know about all homicides committed by the mentally abnormal and not just a selected subgroup. The government white paper, The Health of the Nation, sets targets for suicide prevention in those with severe mental illness ${ }^{7}$; this is not synonymous with contact with the psychiatric services. Jayne Zito's remarkable response to her husband's murder by Christopher Clunis, who suffered from schizophrenia, should inspire us to make much more effort than we do to obtain systematic information and opinions from relatives-of victims of homicide, of mentally abnormal offenders, and of suicides. Thirdly, the inquiry needs to adopt more rigorous investigative methods. Risk factors for violent death can be identified only by more rigorous use of techniques such as case control studies and case ascertainment and data collection can be comprehensive and unbiased only if they are not left to the discretion of clinicians.

Department of Liaison Psychiatry,

ALLAN HOUSE Senior lecturer

Leeds General Infirmary,

Leeds LS1 3EX

1 Confidential inquiry into homicides and suicides by mentally ill people. A preliminary report on homicide.
London: 1994 .
2 Report of the confidential inquiry into homicides sad suicides by mentally ill people Royal College of
Psychiatrists. London: RCP, 1996 .
3 Gunnell D. The potential for preventing suicide: a review of the literature on the effectiveness of
interventions aimed at preventing suicide. Bristol: Health Care Evaluation Unit, 1994 .
4 North East Thames and South East Thames Regional Health Authorities. The report of the inquiry into
the care and treatment of Christopher Clunis. London: HMSO, 1994 .
5 Blom-Cooper L, Hally H, Murphy E. The falling shadow. London: Duckworth, 1995.
6 Martin J. Hospitals in trouble. Oxford: Blackwell, 1984 .
7 Marshall C, Rossman G. Designing qualitative research. 2 nd ed. London: Sage, 1995.
8 Department of Health. The Health of the Nation key area handbook: mental illness. London: DoH,
1993.

\section{Neonatal prevention of iron deficiency}

\section{Placental transfusion is a cheap and physiological solution}

Iron deficiency anaemia in childhood is common even in socially advantaged populations. Low birth weight, early consumption of cows' milk, fast growth rate, and poor dietary iron intake are considered the main risk factors. ${ }^{1}$ Iron enriched infant formula and cereals have been shown to be effective preventive measures. ${ }^{23}$ In developing countries, where iron deficiency anaemia is common and iron enriched formula and cereals are often not available, preventing iron deficiency is not easy: infants who enjoy prolonged and exclusive breast feeding have been found to have good iron status, ${ }^{4}$ but such breastfeeding is increasingly rare; and although medicinal iron is cheap, its use may be culturally unacceptable or difficult to implement. Moreover, dietary iron supplementation can be dangerous in settings where malaria and diarrhoeal infection are endemic ${ }^{25}$ and for children whose iron stores are adequate. ${ }^{6}$

Iron stores at birth show huge individual variations, which correlate with iron stores in the same individuals at 6,9 , and 12 months of age. ${ }^{7}$ This may explain why the iron status of some infants remains sufficient, even if they do not receive adequate daily iron. Dietary iron seems to represent only one of the factors that influence iron status in the first year of life, ${ }^{89}$ probably because iron absorption from formula and cereals is modest and is inhibited by many components of the diet such as polyphenols in fruit and vegetables. If high neonatal iron stores are associated with a good iron status in late infancy, ${ }^{7}$ how can we safely increase neonatal stores?

The merits of early or late clamping of the umbilical cord have been controversial for many years. ${ }^{10}$ According to Usher et $a l,{ }^{11}$ the estimated volume of placental transfusion varies from $20 \%$ to $60 \%$ of the existing blood volume $(54-160 \mathrm{ml})$ depending on the time of clamping and the position in which the infant is held before clamping. ${ }^{12}$ Linderkamp and colleagues estimated that the amount of placental transfusion is about $35 \mathrm{ml} / \mathrm{kg}$ of birth weight when term infants are kept at the level of the vaginal opening and the cord is clamped three minutes after birth. ${ }^{13}$ The same authors have recently investigated the effect of placing the neonate on the mother's abdomen and clamping the cord only once it stops pulsating (Leboyer delivery). ${ }^{14}$ They found that these babies had blood volumes $32 \%$ higher than babies whose cords were clamped immediately after birth. The packed cell volume in cord blood was not affected by placental transfusion, but after 2-4 hours it rose in the group of infants whose cord was clamped late, from 0.51 (SD 0.05$)$ to $0.62(0.06)$. This difference was statistically significant when compared with infants whose cords were clamped early.

A moderate placental transfusion as achieved in the Leboyer delivery does not significantly increase neonatal jaundice, nor does it incur detrimental haemodynamic changes, ${ }^{14}$ although occasional cases of circulatory overload from excessive placental transfusion have been reported. ${ }^{10}$ Moreover, a moderate transfusion of about $20-30 \mathrm{ml} / \mathrm{kg}$ endows about 30-50 mg of "extra" iron and can help prevent or delay depletion of iron stores during late infancy.

Recent research from Denmark favours this hypothesis.? Studying 9 month old infants born in a hospital whose policy was to clamp the cord late, the researchers found serum ferritin values higher than those reported for infants from other European countries, ${ }^{15-17}$ whose cords were assumed to have been clamped immediately after birth. Higher neonatal iron stores associated with late cord clamping could be one explanation for this observation. The positive effects of delayed cord clamping could be even more clinically and economically important among infants in developing countries. For those children a moderate placental transfusion could represent a physiological and inexpensive means of increasing iron stores. At the same time, delayed cord clamping represents a change in routine practice that favours early contact between a mother and her newborn baby. An overview of randomised controlled trials found a statistically significant association between such early contact and subsequent prolonged breast feeding ${ }^{18}$; this could therefore represent another measure to prevent iron deficiency.

Immediate cord clamping is currently routine practice, but its widespread acceptance was not preceded by studies evaluating the effects of depriving neonates of a significant volume of blood. A large clinical trial to compare the short and long term effects of placental transfusion is needed.

ALFREDO PISACANE Senior lecturer

Dipartimento di Pediatria,

Universita di Napoli Federico II,

80131 Naples, Italy 